\title{
A regressão observada no tratamento do desvio fonológico******
}

\section{Relapse observed in the treatment of phonological disorder}

\author{
Mardônia Alves Checalin* \\ Maria Rita Leal Ghisleni** \\ Giovana Ferreira-Gonçalves*** \\ Márcia Keske-Soares**** \\ Helena Bolli Mota****
}

*Fonoaudióloga. Mestre em Distúrbios da Comunicação Humana pela Universidade Federal de Santa Maria (UFSM). Fonoaudióloga Clínica do Instituto de Saúde Auditiva do Pará e da Prefeitura Municipal de Igarapé Miri - PA. Endereço para correspondência: Rua Major Lamarão, 2019 - Belém - PA - CEP 66115-690 (mardoniafono@yahoo.com.br).

**Fonoaudióloga. Mestre em Distúrbios da Comunicação Humana pela UFSM.

Fonoaudióloga Clínica da Prefeitura Municipal de Dom Pedrito - RS.

****inguista. Doutora em Linguística e Letras pela Pontifícia Universidade Católica do Rio Grande do Sul (PUCRS). Professora do Curso de Graduação em Letras e dos Programas de PósGraduação em Letras e em Distúrbios da Comunicação Humana da UFSM.

****Fonoaudióloga. Doutora em Linguística Aplicada pela PUCRS. Professora do Curso de

Fonoaudiologia e do Programa de PósGraduação em Distúrbios da Comunicação Humana da UFSM.

******Trabalho Realizado no Centro de Estudos de Linguagem e Fala (CELF) da UFSM.

Artigo de Estudo de Caso

Artigo Submetido a Avaliação por Pares

Conflito de Interesse: não

Recebido em 04.07.2008.

Revisado em 10.10.2008; 17.03.2009;

24.03.2009; 02.05.2009; 15.02.2010;

08.04.2010.

Aceito para Publicação em 21.08.2010.

Referenciar este material como:

Checalin MA, Ghisleni MRL, Ferreira-Gonçalves G, Keske-Soares M, Mota HB. A regressão observada no tratamento do desvio fonológico. Pró-Fono Revista de $\sum 3$ Atualização Científica. 2010 jul-set;22(3):363-6.

\section{Abstract}

Background: relapse in phonological performance. Aim: to verify relapse in the phonological performance related to sound production in the treatment of phonological disorder. Method: three subjects with phonological disorders, aged 6:0, 7:0, 7:0 years, were treated for phoneme /r/ using the ABAB-Withdrawal and Multiple Probes Model. After a cycle of treatment, the phonemes that presented relapse in terms of production percentage were compared. Results: the results indicate that relapse occurred in the phonological system of all subjects. The involved features were mainly related to the main category. Conclusion: a relationship between the features of the treated phoneme and the ones that presented relapse was observed for all of the studied cases.

Key Words: Speech Disorders; Speech Therapy; Child Language.

\section{Resumo}

Tema: regressão no desempenho fonológico. Objetivo: verificar a regressão no desempenho fonológico quanto à produção dos sons no tratamento do desvio fonológico. Método: três sujeitos com desvios fonológicos, com idade de 6:0, 7:0, 7:0, foram tratados com o /r/ pelo Modelo ABAB-Retirada e Provas Múltiplas. Compararam-se, após um ciclo de tratamento, quais fonemas sofreram processo de regressão no percentual de produção. Resultados: verificou-se que o processo de regressão ocorreu no sistema fonológico de todos os sujeitos. Os traços envolvidos foram, na sua maioria, os de classe principal. Conclusão: há relação entre os traços do fonema tratado e dos que apresentaram regressão nos casos estudados.

Palavras-Chave: Distúrbios da Fala; Fonoterapia; Linguagem Infantil. 


\section{Introdução}

A aquisição não é um processo linear, evidenciando-se quedas na linha ascendente do desenvolvimento, havendo breves períodos de regressão, seguidos pela retomada em direção à especificação de um segmento.

A ocorrência de quedas no desempenho fonológico (regressão) tem sido apontada em aquisição de linguagem, e autores concordam que é desencadeada pela aquisição de um componente mais complexo da gramática ${ }^{1-2}$. A regressão fonológica tem sido observada e descrita na aquisição fonológica normal $^{3}$ e no Desvio Fonológico (DF) ${ }^{4}$.

Crianças com DF apresentam uma desordem desenvolvimental diagnosticada quando a linguagem é pobre em relação às outras habilidades, sem razão aparente ${ }^{5}$. Esta desordem acomete a produção dos sons da fala e pode variar de moderada a severa ${ }^{6}$. As crianças com DF apresentam audição, inteligência não-verbal e status neurológico normais, com significante déficit na habilidade fonológica ${ }^{7}$.

Este trabalho objetivou caracterizar a regressão fonológica na fala de crianças com DF. Traz uma nova perspectiva ao tratamento do $\mathrm{DF}$, contribuindo para a escolha de um som-alvo que potencialize a aquisição.

\section{Método}

Participaram do estudo três sujeitos com DF levemente moderado ${ }^{8}$, selecionados de projeto aprovado no Comitê de Ética em Pesquisa sob número 046/02.

S1 e S3 eram do sexo masculino com 6:0 e 7:0, e S2 era do sexo feminino com 7:0. A avaliação fonológica realizada ${ }^{9}$ considerou adquirido $\mathrm{O}$ segmento com, no mínimo, $80 \%$ de produção correta. Todos foram tratados com /r/ em Onset Medial (OM) por nove sessões de terapia, um ciclo de tratamento, utilizando-se o Modelo "ABAB Retirada e Provas Múltiplas"10.

A regressão foi analisada a partir dos dados da avaliação fonológica inicial (AI) e final (AF). Considerou-se ocorrência de regressão quando a porcentagem de produção do segmento apresentava-se inferior na $\mathrm{AF}$ em relação à AI.

\section{Resultados}

Comparando-se a AI e a AF, evidencia-se a ocorrência de evolução e regressão no desempenho fonológico dos três sujeitos. O número de segmentos que regrediram não ultrapassou o número daqueles que evoluíram, demonstrando a efetividade do tratamento.

Em S1, houve aumento no percentual de produção de sete segmentos (/n/,/s/, /z/, /R/,/l/, /L/ $, / \mathrm{r} /)$, sendo adquiridos dois deles (/n/ e /R/). Em S2, houve a aquisição de um segmento (/L/). Em S3, dos cinco segmentos (/d/, /g/, /l/, /R/, /r/) que apresentaram percentuais de realização superiores na $\mathrm{AF}$, dois deles (/d/ e /g/) foram adquiridos.

$\mathrm{Na} \mathrm{AF}$ dos três sujeitos, observou-se ocorrência de regressão em oito segmentos, estando sete em onset simples e cinco pertencentes à classe das fricativas.

Houve regressão no percentual de produção $\mathrm{de} / \mathrm{v} /(33,3 \%) \mathrm{e} / \mathrm{n} /(17 \%)$ em OI, e/R/ (24\%) em OM para S1; de /s/ $(23,3 \%)$ em CM para S2; e de /S/ (63\% em OI e 47,2\% em OM) e /Z/ (26,36\% em OI e 25\% em OM) para S3 (Gráfico 1).

GRÁFICO 1. Segmentos que sofreram regressão a partir do tratamento fonológico.

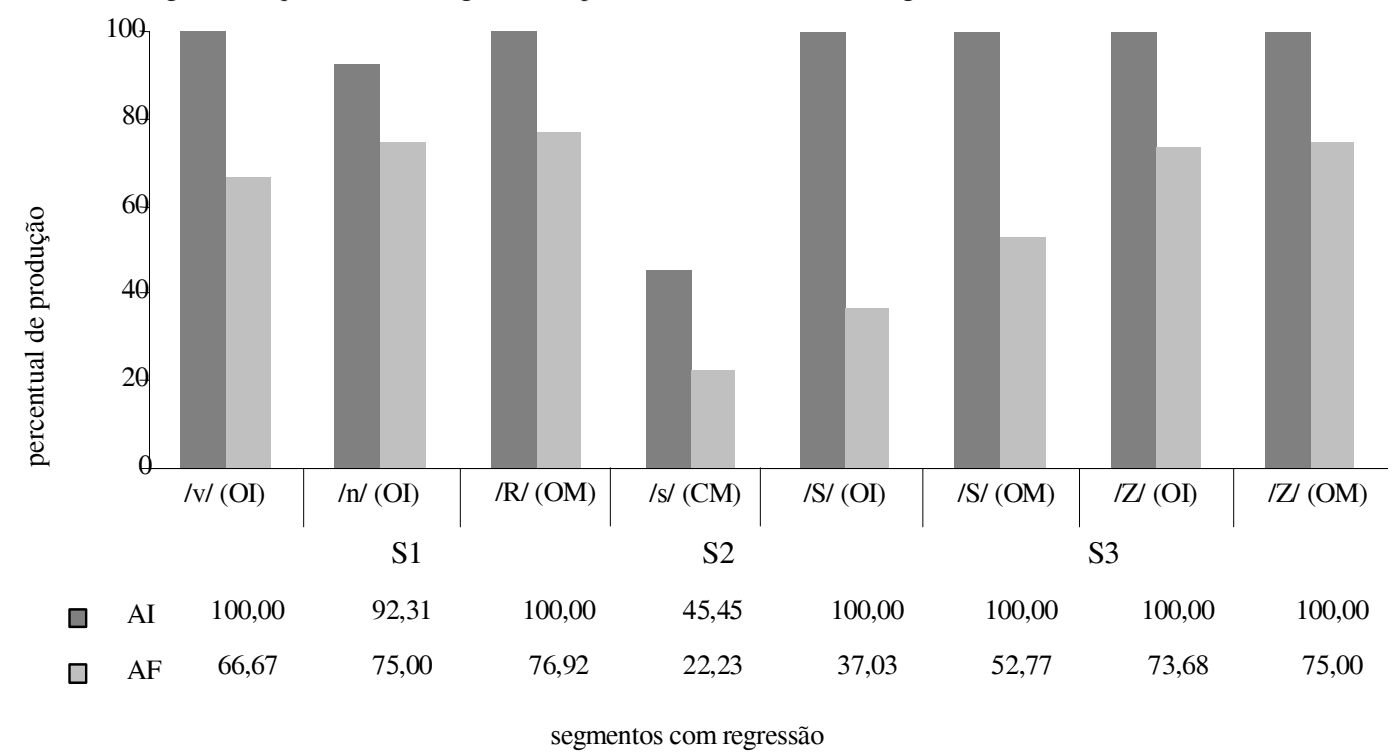




\section{Discussão}

A evolução foi percebida em fonemas pertencentes a todas as classes de sons: plosivas, fricativas, nasais e líquidas. $\mathrm{O}$ mesmo não foi observado na regressão uma vez que o processo não ocorreu em segmentos pertencentes à classe das plosivas.

Apesar dos sujeitos terem o sistema fonológico inicial semelhante e terem sido submetidos ao mesmo tratamento, os sons adquiridos pertenciam a classes de sons distintas. O contrário foi observado em relação aos segmentos que regrediram, que, na sua maioria, pertenciam à classe das fricativas.

Observou-se regressão em segmentos na classe das fricativas, para os três sujeitos; em segmentos adquiridos na AI dos S1 e S3; e em segmento não adquirido do S2. A regressão em segmentos da classe das fricativas sugere uma influência do traço de cavidade oral [+contínuo] comum entre o alvo e os segmentos regredidos.

O modelo de terapia aplicado utiliza a hierarquia implicacional de traços distintivos ${ }^{(1)}$ para selecionar o som-alvo. Este deve estar situado em um maior nível de complexidade, apresentando traços mais marcados, para promover generalização. Antes do tratamento, encontravam-se ausentes segmentos que pertencem à classe das fricativas e líquidas. $\mathrm{O}$ /r/ foi escolhido como alvo, por situar-se no Nível 8 de complexidade na hierarquia adotada.

Pesquisas mostram que não é mais necessário tratar todos os sons nos quais a criança apresenta dificuldade ${ }^{11-12}$. É possível selecionar um alvo de tratamento visando à ocorrência de generalização, que se trata da ampliação da produção e uso correto dos segmentos treinados em outros contextos ou ambientes não-treinados, diminuindo o tempo de tratamento. Para que ocorra generalização, é necessária a seleção de um alvo de tratamento situado em um nível de mais alta complexidade.
Além da generalização, este estudo mostra uma considerável ocorrência de regressão em segmentos estabilizados no sistema dos sujeitos, considerando o tratamento de um segmento situado no nível de mais alta complexidade da hierarquia adotada.

Cabe pensar que se fosse selecionado o alvo menos complexo, talvez a ocorrência de regressão não fosse tão evidente, e o objetivo da generalização de tornar o tratamento mais rápido fosse contemplado efetivamente.

É pertinente analisar até que ponto é válido selecionar um segmento-alvo situado no nível de mais alta complexidade pensando na ocorrência de generalização, quando a aquisição desse segmento pode comprometer a estabilidade do sistema fonológico, através da ocorrência de regressão, tornando o tratamento mais demorado.

Muitos estudos apontam a ocorrência de regressão no processo de aquisição de linguagem, porém nenhum trabalho consultado caracterizou tal processo. A carência de trabalhos sobre o tema impossibilitou a comparação dos resultados dessa pesquisa.

\section{Conclusão}

Observou-se que a regressão foi mais evidente em segmentos da classe das fricativas nos casos estudados, e que a regressão ocorreu, em sua maioria, em segmentos situados em onset simples, adquiridos ou não na AI. Os dados parecem indicar uma relação entre o traço de cavidade oral [cont] do alvo e dos segmentos regredidos.

Na prática clínica, o fonoaudiólogo deve estar atento para a evolução dos sons no sistema fonológico, mas também é importante o conhecimento de que a regressão é comum durante tratamento. Esses processos devem passar a ser considerados na seleção do som-alvo de modo que se possa tornar o tratamento mais rápido e efetivo.

(1). Nesse caso, utilizou-se o Modelo Implicacional de Complexidade de Traços (MICT), baseado na geometria de traços de Clements \& Hume (1995) e o modelo de marcação nas restrições de Calabrese (1995), elaborado por Mota (1996) com o objetivo de representar a as relações existentes entre os traços e a aquisição segmental pelas crianças com DF. 


\section{Referências Bibliográficas}

1. Ingram D. First language acquisition: method, description and explanation. Cambridge: Cambridge University Press; 1989.

2. Miranda ARM. A aquisição do 'r': uma contribuição à discussão sobre seus status fonológico [dissertação]. Porto Alegre: Pontifícia Universidade Católica do Rio Grande do Sul; 1996.

3. Bonilha GFG. Aquisição fonológica do português brasileiro: uma abordagem conexionista da Teoria da Otimidade [tese]. Porto Alegre: Pontifícia Universidade Católica do Rio Grande do Sul; 2004.

4. Keske-Soares M. Terapia fonoaudiológica fundamentada na hierarquia implicacional de complexidade de traços distintivos aplicada em crianças com desvios fonológicos [tese]. Porto Alegre: Pontifícia Universidade Católica do Rio Grande do Sul; 2001.

5. Bishop DVM, Hayios-Thomas ME. Heritability of specific language impairment depends on diagnostic criteria. Genes, Brain and Behavior. 2008;(7):365-72.

6. Sinces L, Taylor G, Freebairn L, Hansen A, Lewis B. Relationship Between Speech-Sound Disorders and Early Literacy Skills in reschool-Age Children: Impact of Comorbid Language Impairment. Journal of Developmental \& Behavioral Pediatrics. 2007;28(6):438-47.
7. Pawlowska M, Leonard LB, Camarata SM, Brown B, Amarata NM. Factors accounting for the ability of children with SLI to learn agreement morphemes in intervention. J. Child Lang. 2008;(35):25-53

8. Shriberg LD, Kwiatkowski J. Phonological disorders I: A diagnostic classification system. Journal of Speech and Hearing Disorders. 1982;(47):226-41.

9. Yavas M, Hernandorena CL, Lamprecht R. Avaliação fonológica da criança, reeducação e terapia. Porto Alegre : Artes Médicas;1991.

10. Tyler A, Figursky GR. Phonetic inventory changes after treating distinctions along an implicational hierarchy. Clinical Linguistics \& Phonetics. 1994;8(2):91-107.

11. Keske-Soares M, Donicht GG, Checalin MA, Ghisleni MRLL. Generalização por 'reforço' ou 'contraste' no tratamento do desvio fonológico. Revista da Sociedade Brasileira de Fonoaudiologia. 2008;13(4):391-7.

12. Barberena LS, Keske-Soares M, Mota HB. Generalização baseada nas relações implicacionais obtida pelo modelo "ABAB-Retirada e Provas Múltiplas". Revista da Sociedade Brasileira de Fonoaudiologia. 2008;13(2):143-43. 